\title{
Veggie burgers in the EU market: a nutritional challenge?
}

\author{
Fatma Boukid ${ }^{1}\left[\right.$ [ $\cdot$ Massimo Castellari ${ }^{1}$
}

Received: 27 April 2021 / Revised: 22 June 2021 / Accepted: 27 June 2021 / Published online: 2 July 2021

(c) The Author(s), under exclusive licence to Springer-Verlag GmbH Germany, part of Springer Nature 2021

\begin{abstract}
Nutritional information of burgers launched in the EU market during 2020 was retrieved from their labels. Products were initially classified into four types: i.e., veggie, red meat-, fish- and poultry-based. Gluten, wheat, and soy were the most declared allergens regardless of the burgers type. Veggie burgers showed levels of energy, fat, and saturate fatty acids (SFA) similar to fish- and poultry-based burgers, but lower than red meat burgers. Compared to conventional burgers, veggie had higher amounts of carbohydrates and sugars and a lower content of proteins, but no difference in salt. Due to the high compositional intra-variability in the veggie burgers, vegetarian and vegan burgers were further analyzed separately. Vegan burgers had higher levels of energy, fat, SFA and protein than vegetarian burgers, but lower carbohydrates and sugars. Once again large differences in the nutritional parameters were observed in both vegan and vegetarian burger categories due to the wide range of ingredients and formulations employed in these types of products. A clear and comprehensive informative labeling is especially needed for vegan and vegetarian burgers to allow the consumer to make a rational decision based on the nutritional facts of these products.
\end{abstract}

\section{Graphic abstract}

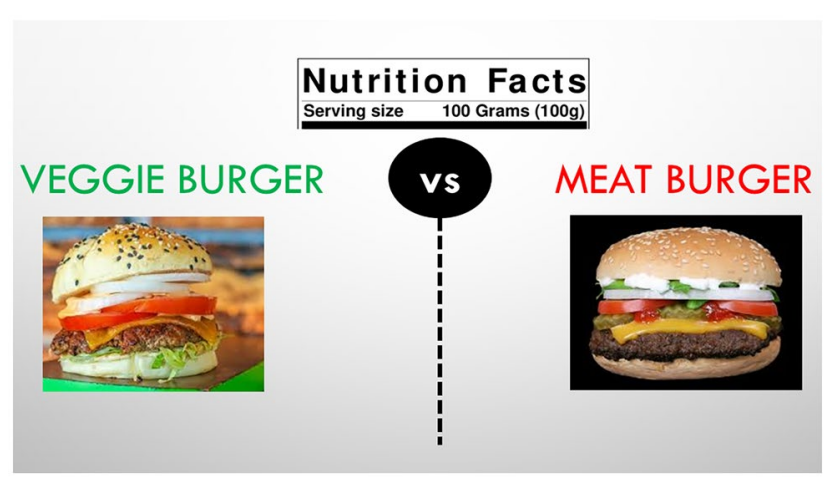

Keywords Burger $\cdot$ Vegan $\cdot$ Vegetarian $\cdot$ Meat $\cdot$ Nutritional labeling $\cdot$ Allergens

\section{Introduction}

Meat burgers are one of the most popular meat products owing to their composition (rich in proteins, fats, minerals, and vitamins), availability, convenience, and affordability.

Fatma Boukid

fatma.boukid@irta.cat

Food Industries, Institute of Agriculture and Food Research and Technology (IRTA), Finca Camps i Armet S/N,

17121 Monells, Spain
Nevertheless, diet rich in meat products can be related to health concerns including colon cancer, obesity, and cardiovascular diseases due to the high content of cholesterol, saturated fatty acids and salt [1-3]. In the frame of European Food and Nutrition Action Plan by World Health Organization (WHO), recommendations have been proposed and specific frameworks have been implemented to reduce population intake of salt, fat and sugar [4]. Beside health concerns, impact of meat production on the environment and animal welfare rights are boosting toward changing eating 
habit toward more sustainable and healthy food consumption patterns $[5,6]$. The shift from a meat-centric to a semi-vegetarian diet (i.e., flexitarian) is giving room to hybrid products made with blends of meat and plant-based ingredients to reduce meat consumption [7].

Hybrid burgers are reformulated products with the aim to reduce the amount of meat in the original recipe and to improve the nutritional composition. For this reason, reformulation focused on finding alternative natural and clean label ingredients to replace partially protein or/and fat without hindering the characteristics of the traditional product. Soy proteins is one of the most used alternative proteins for its functionality and affordability, yet currently its allergenicity contributes into the raise of other less allergenic sources [8]. Cereals proteins deriving from wheat, rice, barley, and oats are included in their different forms (e.g., flour, isolates or concentrates) $[9,10]$. Legume (e.g., pea, lentil and chickpea) are used to partially substitute meat to obtain lowcalorie burgers with high protein and fiber contents [11]. Pseudo-cereals (e.g., quinoa and buckwheat) have attracted much attention because of excellent nutritional ingredients and being less allergenic compounds (gluten-free) and high nutritional value [8]. Mycoproteins and algal proteins are also increasingly included in burger formulations owing to their high nutritional value $[12,13]$. Fat and saturated fat reduction was achieved by replacing animal fat by vegetable and/or marine oils $[12,14,15]$. In response to demands for healthier/functional meat burgers products, bioactive components (e.g., probiotics, fibers, antioxidants, and omega-3) were also added [15-19].

Global plant-based burgers market started as a niche industry for vegan and vegetarian community and now it is growing into a mainstream food [20]. The global plant-based burgers market reached around US\$ 2.7 billion in 2020 and is forecast to increase at compound annual growth rate (CAGR) of 22\% between 2020 and 2030. Europe is expected to emerge as the leader of this market worldwide as it covers nearly half of the global market currently [21]. In the EU, veggie burger market is governed by the Netherlands (18\% of new launches in the 2020), followed by Germany (14.7\%), Spain (8.2\%), Switzerland and Poland (7.6\%), and Portugal (7.1\%) [22]. Veggie burgers can be classified in two products vegan (made from non-animal ingredients) and vegetarian (contain non-meat ingredients such as eggs, mild, and whey proteins). These products are made using non-animal proteins deriving from soy, pea, lentil, wheat or fungi, vegetal oils, starches, colorings/flavoring agents and spices to enable a meat-like experience [23].

There is currently a reasonable debate with the food industry on the nutritional health and wellness of alternative meat products versus those traditional $[23,24]$. The font-of-pack labeling is the tool that can help consumers to make informed choice while purchasing a food product
[25]. Nutritional labeling is important to enable a further understanding of the healthiness of burger products rather than only relying on the mention meat, vegan or plant based or the list of ingredients. Regulation (EU) 1169/2011 on food information to consumers requires mandatory nutrition declaration for energy, total and saturated fats, carbohydrates, sugars, proteins and salt in prepacked foods [25]. In the case of food alternatives such as veggie burgers, labeling remains a source of contention since there is no legally binding definition of the terms "vegan" and "vegetarian" in EU regulation. Regulation (EU) No. 1169/2011), article 36 (3) (b) mentions information "related to suitability of a food for vegetarians or vegans" within the list of voluntary food information. This article leaves largely unclear the labeling of such foods, as it does not provide a definition for "vegan" or vegetarian". Due to the rising interest and demand for vegan and vegetarian foods and the correspondingly increasing relevance of this market segment, a clear definition of these products is indeed required to avoid confusing the consumers. An initiative started by vegetarians and vegans across the EU to identify suitable food [26]. The European food and drink industry and the European Vegetarian Union submitted a joint position to propose a wording which meets the requirements of consumers interested in vegan and vegetarian products [26]. In 2018, European Commission has registered a European Citizens' Initiative entitled "Mandatory food labeling Non-Vegetarian/Vegetarian/Vegan" [27]. No official decision has been taken on either to make an amendment or not yet. The labeling of plant-based alternatives using meat and dairy terms also created a debate in the EU and opinions diverged into two ways: (i) the protection of dairy and meat terms by banning products without meat or dairy from using associated terms (to avoid consumer confusion and misleading) and (ii) the allowance of plantbased alternative to keep meat related nomenclature (and not use terms like "fingers" or "discs"). In 2020, the European parliament has rejected the proposal to ban the use of words like "burger" and "sausages", while prohibiting dairy-like terms [28].

Consumers, vegan or not, are facing the dilemma of choosing the product that can satisfy their dietary style and nutritional expectations. The nutritional labeling might be a way for consumers to compare veggie and animal-based products, and decide the best option. Apart from the ethical factors, the consumer perception is often that vegan products are more nutritional and healthier than their traditional counterparts [29-31].

So, the aim of this work is to answer the question if vegan burgers can be considered more nutritionally equilibrated than the traditional products by carrying out a closer analysis of the nutritional information included in the label of veggie burgers in comparison to the conventional meat- and fishbased products. 
With this objective, labels of a veggies, red meat-, fish-, and poultry-based burgers launched in the EU market in 2020 were analyzed and compared in terms of their main nutritional characteristics and other mandatory information for the consumer, as the indication of allergens within the ingredients.

Finally, a closer focus was put on veggie burgers, by identifying two classes of products, "vegan" and "vegetarian", and investigating their nutritional properties.

\section{Material and methods}

\section{Data collection}

Identification of burgers launched in the global market during the year 2020 was carried out by consulting the Mintel Global New Product Database (Mintel GNPDMintel Group Ltd., London, UK). The Mintel GNPD tracks packaged food and beverage launches in 86 markets worldwide. Each item has detailed product information, such as price, ingredients, claims made and nutritional information, as well as photographs of all sides of the packaging.

Out of the super-category of "foods", the search was focused on the category "Processed Fish, Meat \& Egg Products" that was searched for the keyword "Burger". The Mintel GNPD search was conducted on February14th, 2021, using the search parameters specified in Table 1. The results of all searches were exported to Microsoft Excel (Microsoft Office, Washington, WA, USA).

\section{Data extraction}

Following the $3^{\text {rd }}$ search, burgers were classified into four sub-categories, veggie burgers, red meat burgers, fish burgers and poultry burgers. In a second phase, veggie burgers were further subdivided into vegetarian and vegan products. For all burger products launched in the EU market and having complete mandatory nutritional labeling, energy $(\mathrm{kcal} / 100 \mathrm{~g})$, total fat $(\mathrm{g} / 100 \mathrm{~g})$, saturated fatty acids-SFA $(\mathrm{g} / 100 \mathrm{~g})$, carbohydrates $(\mathrm{g} / 100 \mathrm{~g})$, sugars $(\mathrm{g} / 100 \mathrm{~g})$, protein $(\mathrm{g} / 100 \mathrm{~g})$, and salt $(\mathrm{g} / 100 \mathrm{~g})$ were retrieved. Furthermore, list of ingredients, allergies and suitability for vegan and vegetarian information were retrieved.

\section{Statistical data analysis}

The statistical analysis was carried out using the Statistical Package for Social Sciences software (IBM SPSS Statistics, Version 25.0, IBM corp., Chicago, IL, USA). Energy and nutrient contents per $100 \mathrm{~g}$ of products were analyzed using Kruskal-Wallis non-parametric one-way ANOVA for independent samples with multiple pairwise comparisons and Mann-Whitney non-parametric test for two independent samples.

\section{Results and discussion}

\section{Overview on the global market of burgers with emphasis on EU}

For a better understanding of EU market position, a search was conducted in Mintel database to retrieve all new burger products launched during the year 2020. Results showed that

Table 1 Search strategy used on Mintel Global New Product Database

\begin{tabular}{llll}
\hline Criteria & 1st search & 2nd search & 3rd search \\
\hline $\begin{array}{l}\text { Product name } \\
\text { Sub-category }\end{array}$ & Burger & Burger & Burger \\
& $\begin{array}{l}\text { Processed fish, meat and } \\
\text { egg products }\end{array}$ & $\begin{array}{c}\text { Processed fish, meat } \\
\text { and egg products }\end{array}$ & $\begin{array}{l}\text { Processed fish, meat and egg products } \\
\text { Category }\end{array}$ \\
& Meat substitutes & $\begin{array}{l}\text { Meat substitutes } \\
\text { Fish products }\end{array}$ & Meat substitutes \\
& Meat products & Meat products & \\
& Poultry products & Poultry products & \\
Region & Europe & Europe & Europe \\
& Latin America & & \\
& Asia Pacific & & \\
& North America & & Last complete year \\
& Middle East and Africa & & Carbohydrates (listed on pack); sugars (listed on pack); protein (listed \\
Date & Last complete year & Last complete year & on pack); fat (listed on pack); salt (listed on pack); energy (kcal) (listed \\
Nutrition & - & - & on pack); saturated fat (listed on pack)
\end{tabular}


a total of 262 new veggie burgers, 182 red meat burgers, 28 fish burgers and 41 poultry burgers were launched in the global market (Table 2). These results show clearly the raising trend of consuming plant-based products that boosts food companies to enlarge their portfolios [23]. Vegan and vegetarian products are not new to the market; but more companies now are competing to develop product that mimic the taste and structure of traditional burgers in response to the raising demand. Changes in food habit during Coronavirus disease 2019 (COVID-19) outbreak boosted the raise in veggie burgers and a drop in meat burgers launches (in 2019, global market: 173 veggies, 192 red meat, 21 fish and 39 poultry) [22]. Similarly, US sales of plant-based meat alternatives increased by almost $200 \%$ in April 2020 compared to the same period in 2018 [32]. This can be attributed to several reasons including shortages in meat availability, heighted concern about food safety and health, raise of meat prices (\$255/cwt at March 2020 reaching \$459/cwt at May 2020), and competitive marketing of meat alternatives as producers seize the current disruption as an ideal opportunity to attract new customers [33, 34].

Table 2 summarizes the launches in 2020, where the number of launches varied depending on burger category and the region. In the EU, veggie burgers had the largest share followed by red meat, fish, and poultry burgers. Noteworthy, Europe had the highest number of launches in all categories worldwide [veggies burgers $~ 70 \%$ (184 products out of 262) of total launches in 2020 versus red meat burgers $\sim 48 \%$ ( 87 products out of 182 ) versus fish burgers $\sim 75 \%$ (21 products out of 28) versus poultry burgers $32 \%$ (13 products out of 41)]. A survey in Spain showed this can be due to consumers lowering substantially red meat intake and eating more plant-based food [35]. In Asia, veggie burgers had the highest launches rate followed by red meat and fish, but no new launches in poultry burgers. It was reported that the demand for plant-based protein foods is surging in Asia due to links between wild animal meat and COVID-19 urging consumers to rethink diets [36]. In Latin America, red meat burgers had the highest launches, followed by veggie, poultry, and fish burgers. Indeed, red meat burger is the preferred meat processed product in the Latin market representing $40 \%$ of the market of processed meat considering Brazil and Argentine as one of the most import producers [37]. In the Middle East and Africa, red meat burgers had more new products than veggie burgers, poultry, and fish burgers. This is because the adoption of veganism in this region is a recent trend [38]. In North America, the number of launches was limited, where only six new veggies products were launched in the market, and seven red meat burger, three fish burgers and two poultry burgers.

From a nutritional labeling perspective, not all launched products have all mandatory information set by the EU regulation 1169/2011 [25] that align with those cited in the Codex Alimentarius [39]. Even so, only $90 \%$ of total launched burgers in EU (273 product out of 305) had the mandatory nutritional labeling information. For the other regions having different laws to apply, $19 \%$ of Asian products (20 product out of 62) have nutritional labeling, while almost all products from the Middle East and Africa, Latin and North America did not have it.

\section{Veggie burgers versus meat burgers launched in the EU}

\section{Nutritional labeling}

Focusing on the nutritional labeling of EU burgers launched during 2020 (Fig. 1, Table S1), statistical analysis showed significant difference for all nutrients except salt among veggie, meat, fish and poultry burgers. Red meat burgers showed the highest median values of energy, fat, and SFA. An interesting finding is the similarities between veggie, fish, and poultry burgers in term of energy. The high range of variability of fat and SFA in veggie burgers is quite surprising as values might vary between 39 and $13 \mathrm{~g} / 100 \mathrm{~g}$, respectively. Analysis of the ingredient's lists (Table 3) pointed up that
Table 2 Nutritional labelling of burgers lunched in the global market in 2020

\begin{tabular}{|c|c|c|c|c|c|c|c|c|}
\hline \multirow[t]{2}{*}{ Region } & \multicolumn{2}{|c|}{ Veggie burgers } & \multicolumn{2}{|c|}{ Red meat burgers } & \multicolumn{2}{|c|}{ Fish burgers } & \multicolumn{2}{|c|}{ Poultry burgers } \\
\hline & All & $\begin{array}{l}\text { With } \\
\text { nutritional } \\
\text { labeling* }\end{array}$ & All & $\begin{array}{l}\text { With } \\
\text { nutritional } \\
\text { labeling }\end{array}$ & All & $\begin{array}{l}\text { With } \\
\text { nutritional } \\
\text { labeling }\end{array}$ & All & $\begin{array}{l}\text { With } \\
\text { nutritional } \\
\text { labeling }\end{array}$ \\
\hline Europe & 184 & 170 & 87 & 72 & 21 & 19 & 13 & 12 \\
\hline Asia Pacific & 31 & 12 & 20 & 0 & 0 & 0 & 11 & 0 \\
\hline Latin America & 21 & 0 & 44 & 0 & 2 & 0 & 9 & 0 \\
\hline Middle East and Africa & 20 & 0 & 24 & 0 & 2 & 0 & 6 & 1 \\
\hline North America & 6 & 0 & 7 & 0 & 3 & 0 & 2 & 0 \\
\hline Total & 262 & 182 & 182 & 72 & 28 & 19 & 41 & 13 \\
\hline
\end{tabular}

*Nutritional labeling: energy (kcal/100 g), total fat (g/100 g), saturated fatty acids-SFA (g/100 g), carbohydrates $(\mathrm{g} / 100 \mathrm{~g})$, sugars $(\mathrm{g} / 100 \mathrm{~g})$, protein $(\mathrm{g} / 100 \mathrm{~g})$, and salt $(\mathrm{g} / 100 \mathrm{~g})$ 

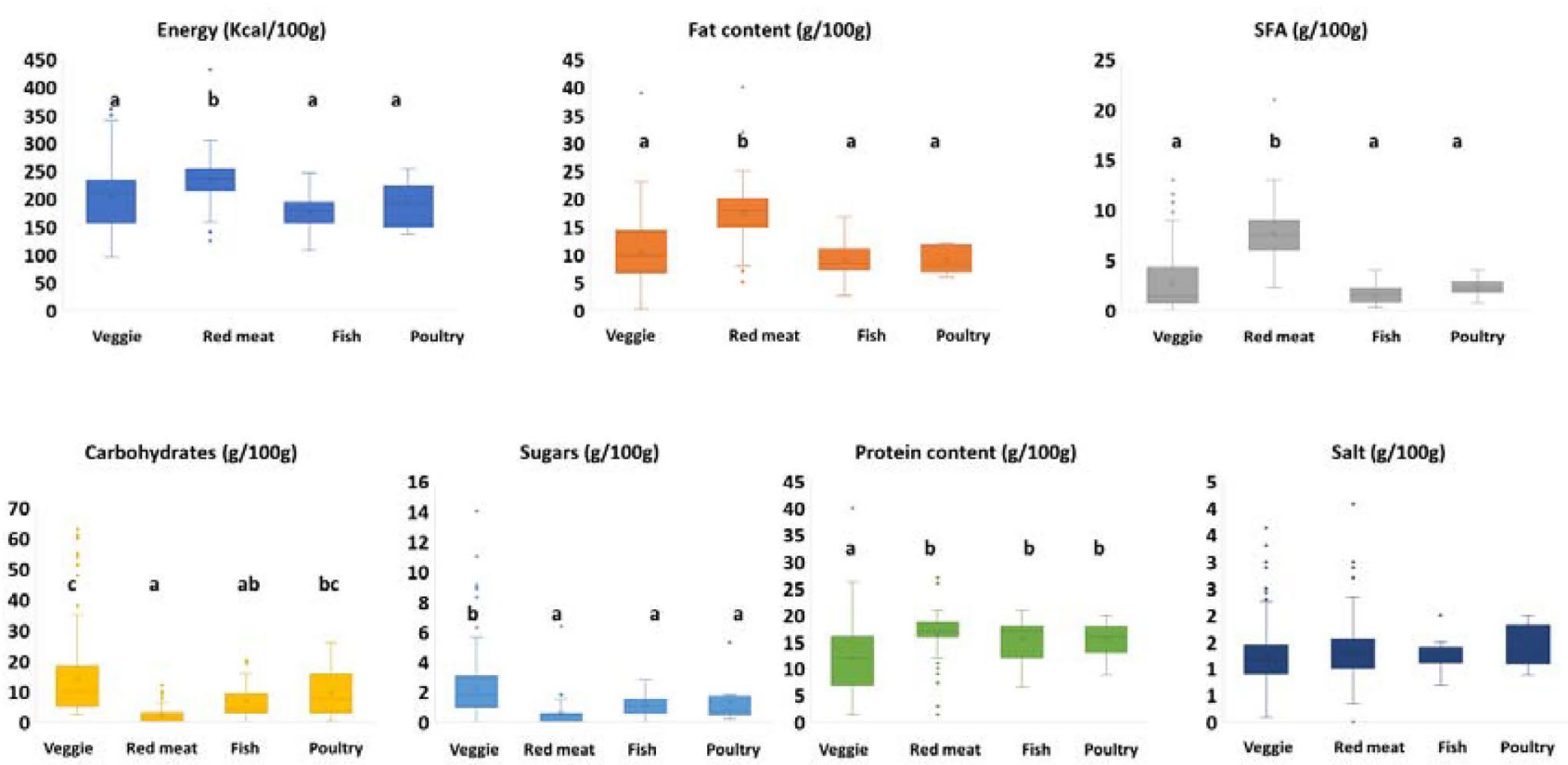

Fig. 1 Nutritional profile of veggie $(N=170)$, red meat burgers $(N=72)$, fish $(N=19)$, and poultry $(N=12)$ burgers launched in the EU market during 2020. Statistical significance based on Kolmogorov-Smirnov test $(p<0.05)$. The box-plot legend: the box is limited

most recipes include vegetal oils having low amount of SFA (e.g., sunflower oil, corn oil, turnip oil, and rapeseed oil), while other formulations contain vegetal oils or fats rich in SFA (e.g., coconut oil and palm oil). In veggie products, butter, milk powder and cheese were also identified as a source of SFAs. Noteworthy, $13 \%(N=9)$ of veggies out of 170 products, were claimed "Low/No/Reduced Saturated Fat"; while $1 \%(N=5)$ of veggies, $3 \%(N=2)$ of red meat and $5 \%$ $(N=1)$ fish burger) were claimed "Low/No/Reduced Fat".

As in part expected the level of carbohydrates in veggie burgers was the highest, as plant-based products contain different starch-rich ingredients like flours, starches, and breadcrumbs. On the contrary, red meat burgers are produced primary from $70 \%$ of meat (pork, veal or beef) and $25-30 \%$ of fat as main ingredients [13].Meat burgers containing plantbased ingredients $(N=46)$ are made by replacing only a part of red meat with vegetables and legumes [carottes $(N=16)$, pea $(N=15)$, soy $(N=5)$ and chickpea $(N=2)]$ in different forms mainly proteins, starches or/and fibers. These products are categorized within meat burgers and consumers have to read the ingredients' list to distinguish them from the traditional meat burgers. In the present study, hybrid products (a part of meat was substituted with a more sustainable source) were not considered separately from meat burgers because the addition level of the plant-based ingredients was not mentioned in all products and when mentioned it did not exceed $15 \%$. Consequently, this makes difficult understanding if the substitution is for functionality reasons (it

by the lower $(\mathrm{Q} 1=25$ th $)$ and upper $(\mathrm{Q} 3=75$ th $)$ quartile; the median is the horizontal line dividing the box; Whiskers above and below the box indicate the 10th and 90th percentiles; outliers: are the points outside the quartile 10-90th percentiles

is a meat burger with plant-based ingredients) or for meat reduction (it is a hybrid product). Poultry and fish burgers had intermediate carbohydrates median values due the inclusion of breadcrumbs or flours/starches deriving from corn, rice, or wheat) that are used as binders. Veggie burgers showed also the highest sugar content, with a high range of variability due to the diversity of ingredients used in the different formulations (e.g., potato and tapioca starches, dextrose, maltodextrin) which are supposed to be added as fat replacers in these products. In some formulation, raw cane sugar, caramel sugar syrup and honey were also declared. No differences were found for this parameter between red meat, fish and poultry burgers.

Protein content was significantly higher in red meat and poultry burgers than in the veggie products. Interestingly, the range of values for this parameter in veggie burgers is extremely variable, reaching a maximum of $40 \mathrm{~g} / 100 \mathrm{~g}$ in one product. This also explains the fact that 76 veggie burgers were claimed high/added of proteins, while other veggie burgers are poor sources of proteins, probably due to the high relevance of starchy ingredients in their formulations.

Salt content did not show any significant differences between the four burger types. This observation does not agree with the results of a survey carried out in a UK supermarket in June 2019, which find out that salt in plant-based mince was much higher (almost six times) than in meat mince, while meat sausages contained $66 \%$ more salt than the plant-based sausages [40]. This positive change could 
be due to the progressive consciousness of the food industry about the need to reduce the use of salt in the new formulations. Anyway, none of the products were claimed low/ no/reduced salt, highlighting the need for further efforts to reduce salt in this type of products. WHO recommends to limit salt intake to no more than $5 \mathrm{~g}$ per day [4]. The current daily salt consumption in most European countries is estimated to range between 8 and $12 \mathrm{~g}$ per day, with few Member States (e.g., Spain, France, and Italy) above and other few (e.g., Germany) below this intake level [41]. Salt intake above of $7.2 \mathrm{~g} /$ day is strongly related to elevated blood pressure and can lead to cardiovascular and renal disease [42]. Again, a high variability in the salt content was observed in both red meat and veggie products. Noteworthy, in some red meat burgers, no added salt was used, as the recipes were made from $100 \%$ minced meat, while, in one red meat burger, the salt reached $\sim 4 \mathrm{~g} / 100 \mathrm{~g}$.

\section{Allergens}

The list of allergens, declared on the package under the Regulation (EU) No. 1169/2011, is summarized in terms of percentages per each type of burgers in Table 4. Only $2.34 \%$ of veggie burgers was claimed gluten-free, while none of the other categories received this denomination. No product (regardless of the category) was claimed dairy-free or allergen- free or lactose-free.

Gluten was the most declared allergens in the case of veggie burgers due to the presence of gluten-containing flours or semolina (e.g., wheat, spelt and barley), derived ingredients (e.g., wheat fiber, wheat proteins and vital gluten) or processed forms (e.g., breadcrumb). These ingredients were also found in fish and poultry burgers, which explains the high percentage of products declared with gluten in both types (42.1 and 66.7\%, respectively). Red meat burgers showed low number of products containing wheat and gluten compared to the other categories.

Dextrose and maltodextrin are commonly used as binders and fat replacers to improve juiciness and tenderness in both veggie and meat, fish and poultry burgers [43], and this explains why wheat was declared as an allergen in many products. As expected, soybean was declared in $49 \%$ of veggie burgers, since it is one of the most used plant protein sources in alternative formulations. Red meat, poultry and fish burgers also may contain soybeans but at less extent.

Veggie burgers contained milk and eggs in $8.8 \%$ and $15.9 \%$ products. Eggs (egg white powder) are the most common and effective binder in vegetarian burgers, while egg replacers including wheat germ, breadcrumbs, oats, and ground flaxseeds are used in vegan burgers. Milk and cheese (e.g., mozzarella, Emmental cheese), milk powder, or whey powder are also added to provide flavoring and functionalities. Likewise, red meat, fish and poultry burgers contained 
Table 4 List of allergens declared on the package of burgers launched in 2020

\begin{tabular}{lcccc}
\hline Allergen & Veggie burgers & Red meat burgers & Fish burgers & Poultry burgers \\
\hline Gluten & $68.8 \%(N=117)$ & $6.9 \%(N=5)$ & $42.1 \%(N=8)$ & $66.7 \%(N=8)$ \\
Wheat & $58.8 \%(N=100)$ & $6.9 \%(N=5)$ & $36.8 \%(N=7)$ & $41.7 \%(N=5)$ \\
Soybeans & $48.8 \%(N=83)$ & $4.2 \%(N=3)$ & $21.0 \%(N=4)$ & $33.3 \%(N=4)$ \\
Milk & $8.8 \%(N=15)$ & $6.9 \%(N=5)$ & $5.3 \%(N=1)$ & $41.7 \%(N=5)$ \\
Eggs & $15.9 \%(N=27)$ & $2.8 \%(N=2)$ & $10.5 \%(N=2)$ & $16.7 \%(N=2)$ \\
Fish & $0.0 \%(N=0)$ & $27.1 \%(N=19)$ & $100.0 \%(N=19)$ & $8.3 \%(N=1)$ \\
Mustard & $3.5 \%(N=6)$ & $2.8 \%(N=2)$ & $10.5 \%(N=2)$ & $33.3 \%(N=4)$ \\
Celery & $7.6 \%(N=13)$ & $0.0 \%(N=0)$ & $0.0 \%(N=0)$ & $0.0 \%(N=0)$ \\
Sulphur dioxide/sulphites & $0.0 \%(N=0)$ & $2.8 \%(N=2)$ & $10.5 \%(N=2)$ & $50.0 \%(N=6)$ \\
Sesame seeds & $1.8 \%(N=3)$ & $0.0 \%(N=0)$ & $0.0 \%(N=0)$ & $0.0 \%(N=0)$ \\
Nuts & $1.2 \%(N=2)$ & $0.0 \%(N=0)$ & $0.0 \%(N=0)$ & $0.0 \%(N=0)$ \\
\hline
\end{tabular}

milk and egg products such as skimmed milk, whey protein concentrate, whey powder, cheese, cream powder, and white egg powder.

Mustard was also declared mostly in fish and poultry burgers since mustard can provide meat tendering and flavoring [44]. Celery and sesame are used as flavoring ingredient [24], and were declared only in a small percentage of veggie products.

Sulphur dioxide/sulphites were employed mostly in poultry burger but was not declared in any of the veggie products. Sulphur dioxide/sulphites are commonly used in burgers as food preservatives to prevent browning or discoloration owing to their antimicrobial, color stabilizing, antibrowning, and antioxidant properties [45]. In Europe, the Regulations (EC) no. 1129/2011 and (EC) no. 1333/2008 authorize the addition of sulfites (up to $450 \mathrm{mg} / \mathrm{kg}$ ) in meat burger (made with a minimum amount of cereal or/and vegetable of $4 \%$ ).

\section{Nutritional labeling of veggie burgers in the EU: vegan versus vegetarian}

As "veggie" includes products with the indication "vegan" or vegetarian" on the package, the nutritional information of these two categories was further analyzed by considering them separately, and several significant differences were highlighted (Fig. 2). Statistically, energy, carbohydrates,
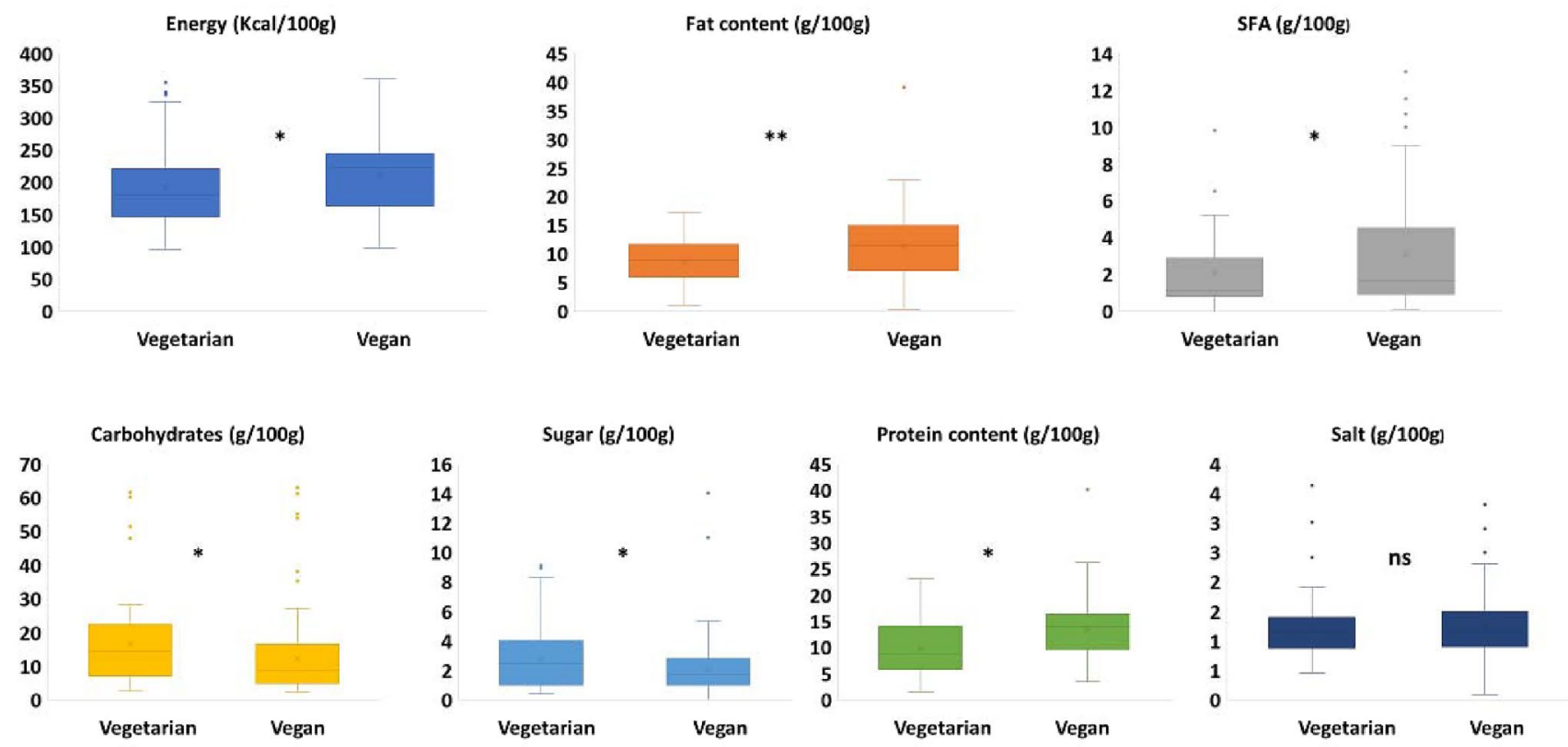

Fig. 2 Nutritional profile of vegetarian burgers $(N=59)$ versus vegan burgers $(N=111)$ launched in the EU market during 2020. Statistical significance based on Kolmogorov-Smirnov test $\left[{ }^{*} p<0.05\right.$, $* * p<0.01, n s$ non-significant $(p>0.05)]$; the box-plot legend: the

box is limited by the lower $(\mathrm{Q} 1=25$ th $)$ and upper $(\mathrm{Q} 3=75$ th $)$ quartile; the median is the horizontal line dividing the box; Whiskers above and below the box indicate the 10th and 90th percentiles; outliers: are the points outside the quartile 10-90th percentiles 
sugars, fat, SFA and proteins varied significantly. Vegan burgers had higher energy, fat, SFA and protein contents than vegetarian burgers, but contained less carbohydrates and sugars. Salt did not vary significantly between both groups. Anyway, a great heterogeneity was observed in the nutritional profile of both groups of products launched in the EU market during 2020, which could confuse the consumer when making the purchase decision.

\section{Conclusion}

The evaluation of the nutritional composition available on the labels of burger products launched in 2020 in EU showed that veggie, red meat, fish, and poultry products differed significantly in their nutrient composition, being veggie burgers nutritionally more similar to poultry and fish burgers. Notwithstanding, it is quite surprising that veggie products recently launched in the market contained more sugars and less proteins than the corresponding meat-based products, being this a clear limitation to be considered nutritionally equilibrated [46]. Another interesting point is that veggie burgers showed a great heterogeneity in their nutritional profile, inclusive between the "vegan" and "vegetarian" categories. Furthermore, vegan burgers had higher energy, fat, SFA and protein than vegetarian burgers, but lower carbohydrates and sugars. This situation could generate confusion in the consumer and emphasizes the importance of a clear and complete label information for a suitable purchase decision. Gluten is the most declared allergen in veggie burgers as well as in fish- and poultry-based products, but other eleven different categories of allergens appeared to some extent in the products launched in the EU market in 2020. Only a small percentage of new products was labeled as gluten-free (only $2.35 \%$ of veggie burgers), while none was claimed allergen-free.

Overall, the veggie market is clearly growing as evidenced by the high number of new products launched in the EU market during 2020. Anyway, it seems that developers of veggie burgers should enhance formulations, by taking profit of the wide range of vegetable ingredients commercially available, to boost their new products as healthy foods and to offer a more nutritionally balanced product, with less sugars, more proteins and allergen-free.

Supplementary Information The online version contains supplementary material available at https://doi.org/10.1007/s00217-021-03808-9.

Author contributions Conceptualization FB and MC; methodology $\mathrm{FB}$ and $\mathrm{MC}$; validation $\mathrm{FB}$ and $\mathrm{MC}$; formal analysis $\mathrm{FB}$; investigation $\mathrm{FB}$ and $\mathrm{MC}$; resources $\mathrm{MC}$; data curation $\mathrm{FB}$; writing-original draft preparation $\mathrm{FB}$; writing - review and editing $\mathrm{FB}$ and MC; project administration MC; funding acquisition MC. All authors have read and agreed to the published version of the manuscript.
Funding This work was supported by CERCA Programme (Generalitat de Catalunya).

\section{Declarations}

Conflict of interest The authors declare no conflict of interest.

Ethical approval This article does not contain any studies with human or animal subjects.

\section{References}

1. Springmann M, Wiebe K, Mason-D'Croz D et al (2018) Health and nutritional aspects of sustainable diet strategies and their association with environmental impacts: a global modelling analysis with country-level detail. Lancet Planet Heal 2:e451-e461. https:// doi.org/10.1016/S2542-5196(18)30206-7

2. Mohamed Z, Terano R, Yeoh SJ, Iliyasu A (2017) Opinions of non-vegetarian consumers among the Chinese community in Malaysia toward vegetarian food and diets. J Food Prod Mark 23:80-98. https://doi.org/10.1080/10454446.2017.1244795

3. Desmond E (2006) Reducing salt: a challenge for the meat industry. Meat Sci 74:188-196. https://doi.org/10.1016/j.meatsci.2006. 04.014

4. Health Organization Regional Office for Europe (2015) European food and nutrition action plan. Health Organization Regional Office, Europe

5. Weinrich R (2019) Opportunities for the adoption of health-based sustainable dietary patterns: a review on consumer research of meat substitutes. Sustain 11:4028

6. Bryant C, Szejda K, Parekh N et al (2019) A survey of consumer perceptions of plant-based and clean meat in the USA, India, and China. Front Sustain Food Syst 3:11. https://doi.org/10.3389/fsufs. 2019.00011

7. Sogari G, Li J, Wang Q et al (2020) Factors influencing the intention to purchase meat-mushroom blended burgers among college students. Food Qual Prefer. https://doi.org/10.1016/j.foodqual. 2020.104169

8. Bahmanyar F, Hosseini SM, Mirmoghtadaie L, Shojaee-Aliabadi S (2021) Effects of replacing soy protein and bread crumb with quinoa and buckwheat flour in functional beef burger formulation. Meat Sci 172:108305. https://doi.org/10.1016/j.meatsci.2020. 108305

9. Boukid F, Rosene S (2020) Grain proteins: challenges and solutions in developing consumer-relevant foods. Cereal Foods World 65:6-10

10. Boukid $\mathrm{F}$ (2021) Oat proteins as emerging ingredients for food formulation: where we stand? Eur Food Res Technol 247:535-544

11. Argel NS, Ranalli N, Califano AN, Andrés SC (2020) Influence of partial pork meat replacement by pulse flour on physicochemical and sensory characteristics of low-fat burgers. J Sci Food Agric 100:3932-3941. https://doi.org/10.1002/jsfa.10436

12. Barros JC, Munekata PES, de Carvalho FAL et al (2021) Healthy beef burgers: effect of animal fat replacement by algal and wheat germ oil emulsions. Meat Sci 173:108396. https://doi.org/10. 1016/j.meatsci.2020.108396

13. Anzani C, Boukid F, Drummond L et al (2020) Optimising the use of proteins from rich meat co-products and non-meat alternatives: nutritional, technological and allergenicity challenges. Food Res Int 137:109575

14. Afshari R, Hosseini H, Mousavi Khaneghah A, Khaksar R (2017) Physico-chemical properties of functional low-fat beef burgers: 
fatty acid profile modification. LWT Food Sci Technol 78:325331. https://doi.org/10.1016/j.lwt.2016.12.054

15. Selani MM, Shirado GAN, Margiotta GB et al (2016) Pineapple by-product and canola oil as partial fat replacers in low-fat beef burger: effects on oxidative stability, cholesterol content and fatty acid profile. Meat Sci 115:9-15. https://doi.org/10.1016/j.meats ci.2016.01.002

16. de Carvalho FAL, Lorenzo JM, Pateiro M et al (2019) Effect of guarana (Paullinia cupana) seed and pitanga (Eugenia uniflora L.) leaf extracts on lamb burgers with fat replacement by chia oil emulsion during shelf life storage at $2{ }^{\circ} \mathrm{C}$. Food Res Int. https:// doi.org/10.1016/j.foodres.2019.108554

17. Bolger Z, Brunton NP, Monahan FJ (2018) Impact of inclusion of flaxseed oil (pre-emulsified or encapsulated) on the physical characteristics of chicken sausages. J Food Eng 230:39-48. https://doi. org/10.1016/j.jfoodeng.2018.02.026

18. Heck RT, Vendruscolo RG, de Araújo EM et al (2017) Is it possible to produce a low-fat burger with a healthy $n-6 / n-3$ PUFA ratio without affecting the technological and sensory properties? Meat Sci 130:16-25. https://doi.org/10.1016/j.meatsci.2017.03. 010

19. Morsy MK, Elsabagh R (2021) Quality parameters and oxidative stability of functional beef burgers fortified with microencapsulated cod liver oil. LWT 142:110959. https://doi.org/10.1016/j. lwt.2021.110959

20. Boukid F, Rosell CM, Rosene S et al (2021) Non-animal proteins as cutting-edge ingredients to reformulate animal-free foodstuffs: present status and future perspectives. Crit Rev Food Sci Nutr. https://doi.org/10.1080/10408398.2021.1901649

21. Future Market Insights (2021) Plant-based burger market: industry analysis, size, share, trends and forecast to 2030. https://www. futuremarketinsights.com/reports/plant-based-burger-market. Accessed 23 Feb 2021

22. Mintel (2021) GNPD—burger. https://www.gnpd.com/sinatra/ search_results/?search_id $=$ sPoMrzCLhN\&page $=0$. Accessed 16 Feb 2021

23. Boukid F (2020) Plant-based meat analogues: from niche to mainstream. Eur Food Res Technol 1:3. https://doi.org/10.1007/ s00217-020-03630-9

24. Bohrer BM (2019) An investigation of the formulation and nutritional composition of modern meat analogue products. Food Sci Hum Wellness 8:320-329

25. European Parliament and of the Council (2011) Regulation (EU) No 1169/2011 of the European Parliament and of the Council of 25 October 2011 on the provision of food information to consumers. https://eur-lex.europa.eu/legal-content/EN/ALL/?uri= CELEX\%3A32011R1169. Accessed 21 Aug 2020

26. European Vegetarian Union (2017) REFIT platform opinion REFIT platform opinion on the submission by the European Vegetarian Union (LtL 548) on the definition of "vegan" and "vegetarian"

27. European Commission (2018) European citizens' initiative: commission registers "mandatory food labelling non-vegetarian/vegetarian/vegan" initiative'. https://ec.europa.eu/commission/press corner/detail/en/IP_18_6317. Accessed 24 Feb 2021

28. Food Navigator (2020) "Vegan cheese" banned but "veggie burger" still on the table, votes European Parliament. https://www. foodnavigator.com/Article/2020/10/23/Vegan-cheese-bannedbut-veggie-burger-still-on-the-table-votes-European-Parliament. Accessed 20 Mar 2021

29. Michel F, Hartmann C, Siegrist M (2021) Consumers' associations, perceptions and acceptance of meat and plant-based meat alternatives. Food Qual Prefer 87:104063. https://doi.org/10. 1016/j.foodqual.2020.104063

30. Alcorta A, Porta A, Tárrega A et al (2021) Foods for plant-based diets: challenges and innovations. Foods 10:293
31. Tso R, Lim AJ, Forde CG (2021) A critical appraisal of the evidence supporting consumer motivations for alternative proteins. Foods 10:24

32. Financial Times (2020) Pandemic accelerates shift to meat substitutes. https://www.ft.com/content/0127984a-6def-4040-9bca002b6ffd4e0a. Accessed 26 Feb 2021

33. Attwood S, Hajat C (2020) How will the COVID-19 pandemic shape the future of meat consumption? Public Health Nutr 23:3116-3120

34. Lusk JL, Tonsor GT, Schulz LL (2021) Beef and pork marketing margins and price spreads during COVID-19. Appl Econ Perspect Policy 43:4-23. https://doi.org/10.1002/aepp.13101

35. Batlle-Bayer L, Aldaco R, Bala A et al (2020) Environmental and nutritional impacts of dietary changes in Spain during the COVID-19 lockdown. Sci Total Environ 748:141410. https://doi. org/10.1016/j.scitotenv.2020.141410

36. Master F (2020) Asia pivots toward plants for protein as coronavirus stirs meat safety fears I Reuters. https://www.reuters.com/ article/us-health-coronavirus-asia-food/asia-pivots-toward-plantsfor-protein-as-coronavirus-stirs-meat-safety-fears-idUKKCN224 047? edition-redirect=uk. Accessed 25 Feb 2021

37. Market Data Forecast (2020) Latin America processed meat market | 2020-2025 | Mexico, Brazil, Argentina, Chile. https://www. marketdataforecast.com/market-reports/latin-america-processedmeat-market. Accessed 25 Feb 2021

38. Morder Intelligence (2021) Middle East \& Africa plant-based meat and dairy products market - growth I trends I forecast. https:// www.mordorintelligence.com/industry-reports/middle-east-andafrica-plant-based-meat-and-dairy-products-industry. Accessed 23 Feb 2021

39. Codex Committee on Food Labelling (2019) E Agenda Item $8 \mathrm{CX} /$ FL 19/45/8 joint FAO/WHO food standards programme codex committee on food labelling forty-fifth session. J Allergy Clin Immunol. https://doi.org/10.1016/j.jaci.2010.10.007

40. Curtain F, Grafenauer S (2019) Plant-based meat substitutes in the flexitarian age: an audit of products on supermarket shelves. Nutrients. https://doi.org/10.3390/nu11112603

41. EC (2020) Dietary salt/sodium I EU Science Hub. https://ec. europa.eu/jrc/en/health-knowledge-gateway/promotion-preve ntion/nutrition/salt. Accessed 25 Feb 2021

42. Bakaloudi DR, Halloran A, Rippin HL et al (2020) Intake and adequacy of the vegan diet. A systematic review of the evidence. Clin Nutr. https://doi.org/10.1016/j.clnu.2020.11.035

43. de Carvalho GR, Milani TMG, Trinca NRR et al (2017) Textured soy protein, collagen and maltodextrin as extenders to improve the physicochemical and sensory properties of beef burger. Food Sci Technol 37:10-16. https://doi.org/10.1590/1678-457X.31916

44. Gullón P, Astray G, Gullón B et al (2021) Inclusion of seaweeds as healthy approach to formulate new low-salt meat products. Curr Opin Food Sci 40:20-25

45. D'Amore T, Di Taranto A, Berardi G et al (2020) Sulfites in meat: occurrence, activity, toxicity, regulation, and detection. A comprehensive review. Compr Rev Food Sci Food Saf 19:2701-2720. https://doi.org/10.1111/1541-4337.12607

46. EFSA (2016) Scientific opinion on principles for deriving and applying dietary reference values. EFSA J. https://doi.org/10. 2903/j.efsa.2010.1458

Publisher's Note Springer Nature remains neutral with regard to jurisdictional claims in published maps and institutional affiliations. 